\title{
Impaired endothelium-dependent and endothelium- independent systemic vasodilatory reserve in pulmonary hypertension regardless the clinical group: A generalized dysfunction beyond the pulmonary arteries?
}

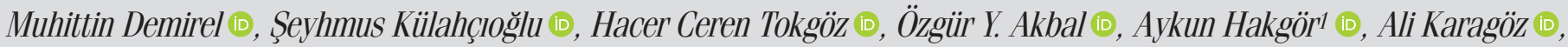

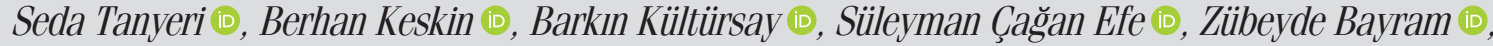 \\ Ibrahim Halil Tanboğa² (D), Nihal Özdemir (1), Cihangir Kaymaz () \\ Department of Cardiology, University of Health Sciences, Hamidiye Faculty of Medicine, \\ Koşuyolu Yüksek İhtisas Training and Research Hospital; İstanbul-Turkey \\ ${ }^{1}$ Department of Cardiology, Bingöl State Hospital; Bingöl-Turkey \\ ${ }^{2}$ Department of Biostatistics, Nişantaşı University; İstanbul-Turkey
}

\section{ABSTRACT}

Objective: Endothelium-dependent (ED) and endothelium-independent (EI) flow-mediated vasodilatation (FMD) have been used as measures of systemic arterial vasodilatory reserve. In this study, we aimed to assess both ED-FMD and EI-FMD in different groups with pulmonary hypertension $(\mathrm{PH})$, and to investigate the relationship of these measures with clinical, echocardiographic, and invasive parameters of diseases severity and targeted treatment status.

Methods: Our study population comprised 41 patients with PH [28 (68.2\%) women, age $46.3 \pm 19.6$ years] including idiopathic pulmonary arterial hypertension, Eisenmenger syndrome, and chronic thromboembolic PH in whom diagnosis were confirmed in accordance with current guidelines and 17 age and sex-matched healthy controls. The brachial artery (BA) was used for assessment of FMD with Duplex ultrasound, and serial changes in diameter were recorded at baseline, 1, and 3 minutes after termination of 2-minute external occlusive compression for ED-FMD, and after sublingual intake of glycerol trinitrate for El-FMD, respectively.

Results: Compared with controls, overall the PH group showed significantly lower ED-FMD $(0.65 \pm 0.21$ vs. $0.30 \pm 0.23$ and $0.65 \pm 0.18$ vs. $0.24 \pm 0.21)$ and El-FMD ( $0.67 \pm 0.15$ vs. $0.37 \pm 0.25$ and $0.75 \pm 0.20$ vs. $0.32 \pm 0.24)$ responses at $1^{\text {st }}$ and $3^{\text {rd }} \min (p<0.001$ for all). All these changes in the values of ED-FMD and EI-FMD were comparable among the PH subgroups. Neither ED-FMD nor EI-FMD were correlated with measures of PH severity and targeted therapy (TT) status $(p>0.05)$.

Conclusion: Our results suggest an impaired BA vasodilatory reserve in patients with PH regardless of the clinical subgroup. Although these findings seem to be consistent with systemic dysfunction, acute FMD may not reflect the severity of PH and cannot be used as a potential surrogate for outcome in this setting.

Keywords: chronic pulmonary hypertension, endothelium, pulmonary circulation, right ventricle

Cite this article as: Demirel M, Külahçıŏlu Ş, Tokgöz HC, Akbal ÖY, Hakgör A, Karagöz A, et al. Impaired endothelium-dependent and endothelium-independent systemic vasodilatory reserve in pulmonary hypertension regardless the clinical group: A generalized dysfunction beyond the pulmonary arteries? Anatol $J$ Cardiol 2021; 25: 733-40.

\section{Introduction}

Pulmonary hypertension (PH) is a progressive and debilitating disease resulting in right ventricular dysfunction, heart failure, and eventually death (1-3). Group 1 PH or pulmonary arterial hypertension (PAH) has been considered as a prototype of hemodynamically pre-capillary PH generalized to other PH subsets, except group $2 \mathrm{PH}$ which is characterized by post-capillary pressure overload owing to left-sided cardiovascular pathologies (1-3). The main pathologic pathway of PAH is narrowing of the pulmonary artery lumen because of vasoconstriction, arterial concentric remodeling, and in situ thrombosis mainly involv-

Address for Correspondence: Dr. Cihangir Kaymaz, Kartal Koşuyolu Yüksek İhtisas Eğitim ve Araştırma Hastanesi, Kardiyoloji Kliniği, İstanbul-Türkiye

Phone: +90 2165001500 E-mail: cihangirkaymaz2002@yahoo.com

Accepted Date: 17.09.2021 Available Online Date: 30.09.2021

(C) Copyright 2021 by Turkish Society of Cardiology - Available online at www.anatoljcardiol.com DOI:10.5152/AnatolJCardiol.2021.474 


\section{HIGHLIGHTS}

- Although flow-mediated vasodilatation has been used as a measure of systemic arterial vasodilatory reserve in cardiovascular diseases, its clinical relevance in patients with pulmonary hypertension remains undetermined.

- Our study demonstrated that brachial artery vasodilatory reserve was significantly compromised in patients with pulmonary hypertension than in healthy subjects.

- Although pulmonary endothelial system is the main target of pulmonary hypertension treatment, presence of generalized endothelial dysfunction should also be considered.

ing the distal pulmonary arteries (1-3). Pulmonary vascular endothelium has a primary role in maintaining low pulmonary vascular resistance. Increased vasoconstriction in pulmonary vasculature owing to increased endothelin-1 and thromboxaneA2 levels plays a critical role in pathogenesis of PAH (1-4). However, pulmonary arterial hemodynamics seem to be dependent on those in systemic arterial circulation, and current studies in PAH suggest a systemic disease comprising abnormal endothelial responses to vasodilatory triggers, metabolic dysregulation, and inflammation which might be associated with clinical outcome $(5,6)$. All of the three pathways which have been proven to be involved in the pathogenesis of PAH are essentially related with endothelial dysfunction (2-5), and currently available specific therapies targeted at these pathways not only provide endothelium-mediated vasodilatory effects and antiproliferative effects on pulmonary vasculature, but also vasodilatory effects on different components of systemic arterial circulation (5-13). However, peripheral vasodilatory effects of drugs proven for PAH therapies seem to be ignored despite the robust evidence for effectiveness of these agents on systemic arterial circulation, such as accelerated healing of Raynaud's syndrome and skin ulcers via cutaneous vasodilation in scleroderma with bosentan and iloprost, improvement in erectile dysfunction and systemic vasodilation in heart failure with sildenafil, portal vein vasodilation with epoprostenol, and improvement in limb blood flow in peripheral arterial disease with treprostinil and iloprost (5-13).

Most of the blood vessels respond to shear stress by vasodilatation known as flow-mediated dilatation (FMD), and the most effective mediator of FMD is endothelium-derived nitric oxide (NO) $(5,14-20)$. Although endothelium-dependent (ED) and endothelium-independent (EI) FMD have been used for noninvasive assessment of systemic arterial vasodilatory reserve in various cardiovascular diseases, their clinical relevance in patients with different $\mathrm{PH}$ etiologies remains to be determined $(5,14-20)$.

In this study, we aimed to assess both ED-FMD and EI-FMD in different groups of $\mathrm{PH}$, and to investigate the relationship of these measures with clinical, echocardiographic, and invasive parameters of disease severity.

\section{Methods}

The study population comprised of 41 patients with $\mathrm{PH}$ [age $46.32 \pm 19.61$ years, $28(68.3 \%)$ women] and 17 healthy controls who underwent assessment of FMD in brachial artery (BA) with duplex ultrasound. The $\mathrm{PH}$ population were as follows; idiopathic PAH ( $n=17)$, Eisenmenger syndrome $(n=17)$, and chronic thromboembolic PH (CTEPH) $(n=7)$. Healthy volunteers with normal echocardiographic right and left ventricular functions and patients with tricuspid regurgitation velocities $<2.8$ without supportive $\mathrm{PH}$ criteria, clinical history, and were free of a history of recent cardiovascular diseases, alcohol, drug, or tobacco use were included (2).

The study protocol was approved by the Ethics Committee and was performed according to the guidelines of the Declaration of Helsinki. A written informed consent was obtained from all the patients before enrollment.

The World Health Organization functional status of $\mathrm{PH}$ group varies from class II to III, and none of them was hospitalized last month before inclusion in the study. The diagnostic criteria of the European Society of Cardiology and the European Respiratory Society $2015 \mathrm{PH}$ guidelines were used for hemodynamic and clinical definitions of $\mathrm{PH}$, and hemodynamic definitions of $\mathrm{PH}$ was based on the criteria including the mean pulmonary arterial pressure of (mPAP) $\geq 25 \mathrm{~mm} \mathrm{Hg}$, pulmonary capillary pressure (PCWP) or left ventricle end-diastolic pressure (LVEDP) 15, and pulmonary vascular resistance (PVR) $\geq 3$ measured by heart catheterization (2).

Definition of Eisenmenger syndrome: Eisenmenger syndrome is elevated pulmonary vascular resistance driving rightto-left intracardiac or great arterial shunting leading to systemic arterial desaturation (2).

Definition of CTEPHT: The diagnosis based on findings of $\mathrm{PH}$ obtained after at least 3 months of effective anticoagulation, with mismatched perfusion defects on lung scan and specific diagnostic signs for CTEPH seen by multidetector CT angiography or invasive angiography (2).

Exclusion criteria: The patients with known coronary artery disease, peripheral arterial disease, cerebrovascular disease, systemic hypertension, diabetes mellitus, those who used drugs that could affect endothelial functions such as angiotensin converting enzyme inhibitor, angiotensin receptor blocker, alpha or beta blockers, nitrate, and alcohol or smoking history were excluded.

In accordance with the guidelines for ultrasound assessment of ED flow-mediated vasodilation of the brachial artery, Duplex assessment of BA for FMD was performed in a quiet and temperature controlled room, and under ECG monitorization (14). The patients and controls were positioned supine with the arm in a comfortable position for imaging the brachial artery. The brachial artery was imaged above the antecubital fossa in the longitudinal plane. A segment with clear anterior and posterior 
intimal interfaces between the lumen and vessel wall was selected for continuous 2D grayscale imaging. Patients with suboptimal imaging were excluded.

A linear array transducer with a frequency of $10 \mathrm{MHz}$, attached to a high-quality mainframe ultrasound system (General Electric Medical-Systems, Horten, Norway) was used to acquire images. Serial changes in diameter were recorded at baseline, 1, and 3 minutes after termination of 2-minute external occlusion for ED-FMD, and glyceryl trinitrate (GTN) was used for evaluation of EI-FMD after ED-FMD session. After 15 minutes of rest, the patients were given $400 \mathrm{mcg}$ of GTN sublingually (14). At the $1^{\text {st }}$ and $3^{\text {rd }}$ minute of GTN exposure, arterial radius was recorded as nitrate phase. Percent FMD was described as percentage increasing of arterial radius after basal recording.

$\mathrm{FMD} \%=[(\mathrm{FMD} 1$ st $\mathrm{min}-$ basal radius $) /$ basal radius $] \times 100$.

\begin{tabular}{|llll|}
\hline \multicolumn{4}{|l|}{ Table 1. Baseline demographic and clinical variables } \\
\hline Variables & Patients & Controls & $P$-value \\
\hline Age (years) & $46.32 \pm 19.61$ & $42.35 \pm 15.29$ & 0.463 \\
Sex (female) & $28(68.3 \%)$ & $10(58.8 \%)$ & 0.698 \\
Body mass index $\left(\mathrm{kg} / \mathrm{m}^{2}\right)$ & $24.39 \pm 5.39$ & $23.95 \pm 4.37$ & 0.763 \\
\hline Continuous variables presented as mean \pm standard deviation \\
\hline
\end{tabular}

Table 2. Medications in subgroups of patients with pulmonary hypertension

\begin{tabular}{|lccc|}
\hline Drug type & IPAH (n=17) & Eisenmenger (n=17) & CTEPH (n=7) \\
\hline Bosentan n (\%) & $13(76)$ & $12(70)$ & - \\
Tadalafil, n (\%) & $11(64)$ & $11(64)$ & - \\
Sildenafil, n (\%) & $1(6)$ & $1(6)$ & - \\
Iloprost, n (\%) & $1(6)$ & - & - \\
Treprostinil, n (\%) & $2(12)$ & $1(6)$ & - \\
Riociguat, n (\%) & - & - & $6(85)$ \\
Diuretic, n (\%) & $6(35)$ & $5(29)$ & $5(71)$ \\
Warfarin, n (\%) & $2(12)$ & $2(12)$ & $7(100)$ \\
Ambrisentan, n (\%) & $1(6)$ & - & - \\
\hline $\begin{array}{l}\text { IPAH - idiopathic pulmonary arterial hypertension, CTEPH - chronic thromboembolic } \\
\text { pulmonary hypertension }\end{array}$ &
\end{tabular}

All these parameters were recorded in the same environment with the same equipment (14).

The relationship between FMD\% and echo measures, invasively measured pulmonary arterial systolic, diastolic, and mean pressures, pulmonary and systemic vascular resistance, WHO functional class, six-minute walking distance (6MWD), and targeted treatments were also evaluated.

\section{Statistical analysis}

The data analysis was performed using Number Cruncher Statistical Systems and R version 4.02 (Number Cruncher Statistical System, 2007, Kaysville, Utah, USA, and Vienna, Austria respectively). The distribution of each continuous variable was tested for normality using the Shapiro-Wilk test and expressed as mean \pm standard deviation. Variables with a skewed distribution were expressed as median value [interquartile range (IQR)]. Normally distributed variables were performed using the unpaired t-test or one-way analysis of variance (ANOVA) for continuous variables. Non-normally distributed variables were performed using the Kruskal-Wallis test or Friedman test, Dunn's and Durbin-Conover post-hoc test were used respectively. The categorical variables are expressed in frequencies and percentages. The Pearson's chi-squared test was used to compare categorical variables. Correlation between variables was evaluated using Spearman's correlation analysis.

Sample size calculation: According to repeated measure tests, to assess whether our test and design had sufficient sensitivity (power $>0.8$ ) to detect that difference within the group when the effect size " $f$ " is $>0.20$, number of repeated measurements 3 and alfa error probability 0.05 , we would need sample sizes of at least 38. A p-value was set at $<0.05$.

\section{Results}

The age, sex, and body mass index were comparable between $\mathrm{PH}$ and control groups (Table 1). Medications in $\mathrm{PH}$ subgroups are given in Table 2.

Control group, IPAH, Eisenmenger, and CTEPH patients showed significant increases in the "ischemia-flow mediated dilatation" at the $1^{\text {st }}$ and $3^{\text {rd }}$ minutes compared with baseline ( $p=0.001, p=0.001, p=0.001$, and $p=0.002$, respectively) (Table 3 ). The change from basal to $3^{\text {rd }}$ minute measurements were statistically significant among $\mathrm{PH}$ subgroups ( $\mathrm{p}=0.001$ and $\mathrm{p}<0.001)$.

Table 3. Serial changes in ischemia-flow mediated dilatation (ED-FMD) and nitrate mediated dilatation (EI-FMD) across the PH group

\begin{tabular}{|c|c|c|c|c|c|c|c|c|}
\hline \multirow[b]{2}{*}{ Groups } & \multicolumn{4}{|c|}{ ED-FMD } & \multicolumn{4}{|c|}{ El-FMD } \\
\hline & Basal & $1^{\text {st }}$ minute & $3^{\text {rd }}$ minute & $P$-value & Basal & $1^{\text {st }}$ minute & $3^{\text {rd }}$ minute & $P$-value \\
\hline Controls & $3.20(2.6-3.4)$ & $3.8(3.4-4.1)$ & $3.8(3.3-4.0)$ & 0.001 & $3.2(2.73 .4)$ & $3.8(3.4-4.2)$ & $3.9(3.3-4.1)$ & 0.001 \\
\hline Eisenmenger & $3.2(3.0-3.9)$ & $3.4(3.2-4.1)$ & $3.4(3.1-4.0)$ & 0.001 & $3.2(2.9-3.8)$ & $3.5(3-4)$ & $3.4(3.0-4.2)$ & 0.001 \\
\hline CTEPH & $3.3(3.0-3.4)$ & $3.6(3.3-3.7)$ & $3.5(3.3-3.8)$ & 0.002 & $3.3(3.0-3.4)$ & $3.8(3.2-3.8)$ & $3.7(3.2-4.0)$ & 0.004 \\
\hline
\end{tabular}

Continuous results, continuous variables given as median and interquartile range ( 1 st to $3^{\text {rd }}$ ).

ED - endothelium dependent, EI - endothelium independent, FMD - flow-mediated vasodilatation, PH - pulmonary hypertension, IPAH - idiopathic pulmonary arterial hypertension, CTEPH - chronic thromboembolic pulmonary hypertension 


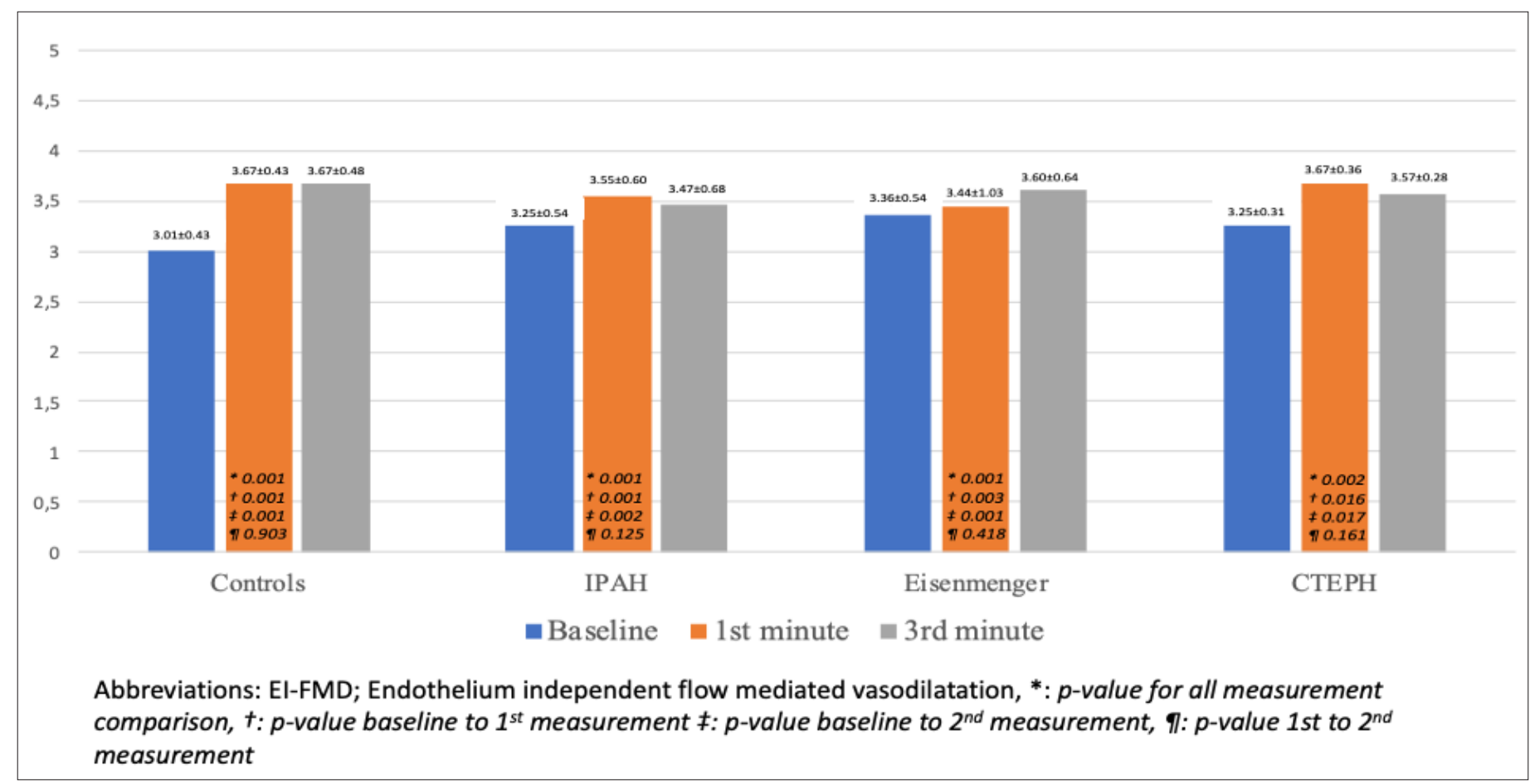

Figure 1. Serial endothelium-dependent and flow-mediated vasodilatation changes across the groups

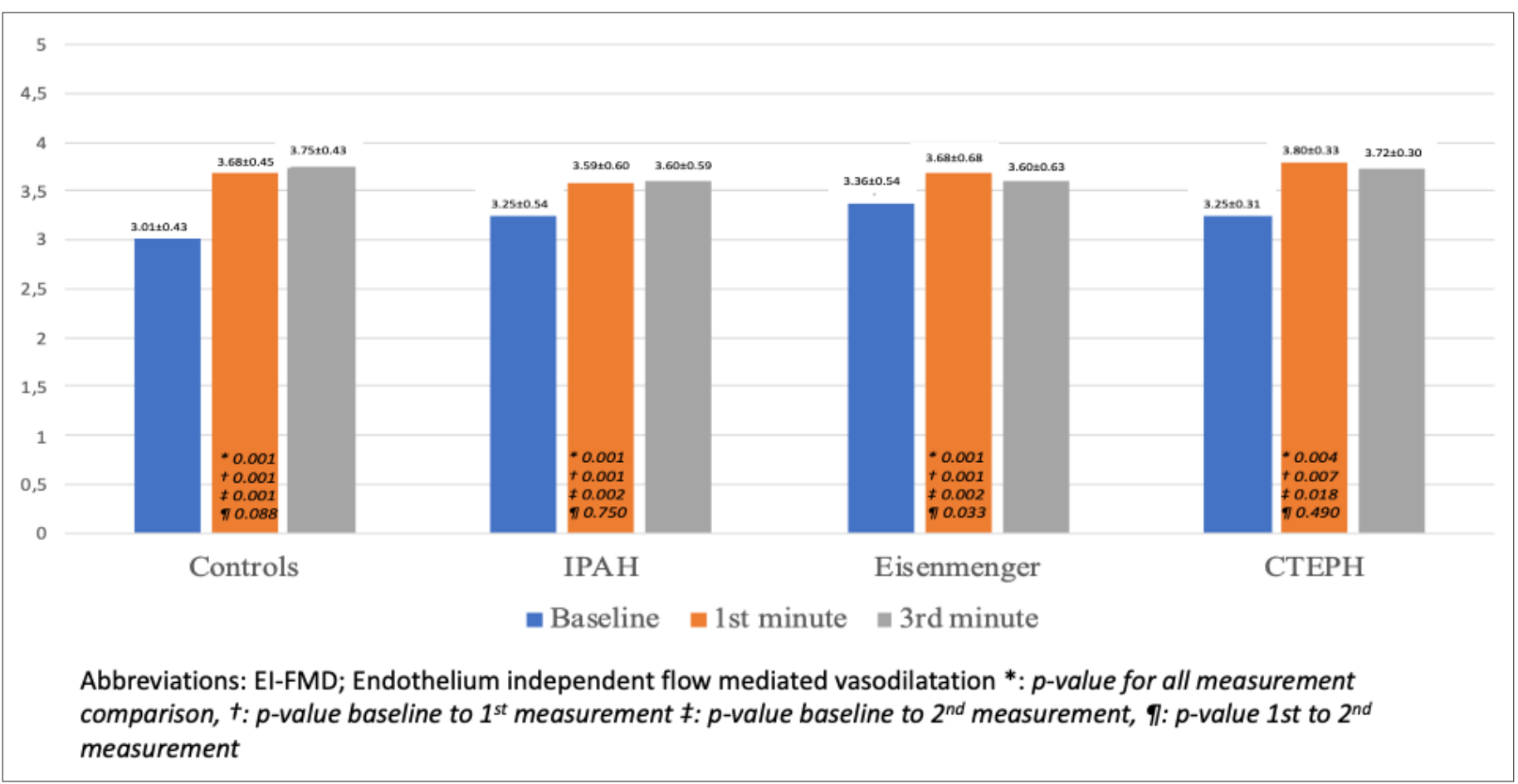

Figure 2. Serial endothelium-independent and flow-mediated vasodilatation changes across the groups

However, the change between the $1^{\text {st }}$ minute and $3^{\text {rd }}$ minute measurements were comparable among $\mathrm{PH}$ subgroups ( $p>0.05$ )

(Fig. 1, Table 4). Compared with the control group, IPAH group $(p=0.001)$, Eisenmenger group $(p=0.001)$ and CTEPH group $(p=0.003)$ showed significantly lower ischemia change from baseline to $3^{\text {rd }}$ minute measurements, $(p<0.001)$. However, $3^{\text {rd }}$ minute ischemia change was comparable among $\mathrm{PH}$ subgroups ( $p>0.05$ ) (Table 4).

In the control, IPAH, Eisenmenger, and CTEPH groups, "nitrate mediated vascular dilatation" at the $1^{\text {st }}$ and $3^{\text {rd }}$ minutes were statistically different than the basal measures $(p=0.001$, $p=0.001, p=0.001$, and $p=0.004$, respectively). Moreover, changes from the baseline to the $1^{\text {st }}$ and $3^{\text {rd }}$ minutes and from the $1^{\text {st }}$ to 


\begin{tabular}{|c|c|c|c|c|c|}
\hline Difference (change) & Controls & IPAH & Eisenmenger & CTEPH & $\boldsymbol{P}$-value \\
\hline Basal to $3^{\text {rd }}$ minute & $0.6(0.5-0.8)$ & $0.2(0.2-0.4)$ & $0.3(0.1-0.4)$ & $0.3(0.2-0.4)$ & 0.001 \\
\hline $1^{\text {st }}$ to $3^{\text {rd }}$ minutes & $0.0(0.0-0.1)$ & $0.0(0.0-0.1)$ & $0.0(0.0-0.1)$ & $0.1(0.0-0.1)$ & 0.566 \\
\hline Basal to $1^{\text {st }}$ minute & $0.6(0.4-0.8)$ & $0.3(0.2-0.4)$ & $0.3(0.1-0.4)$ & $0.3(0.1-0.5)$ & 0.001 \\
\hline Basal to $3^{\text {rd }}$ minute & $0.6(0.5-0.8)$ & $0.2(0.2-0.4)$ & $0.3(0.1-0.4)$ & $0.3(0.2-0.5)$ & 0.001 \\
\hline $1^{\text {st }}$ to $3^{\text {rd }}$ minutes & $0.0(0.0-0.1)$ & $0.0(0.0-0.1)$ & $0.0(0.0-0.1)$ & $0.1(0.0-0.1)$ & 0.028 \\
\hline
\end{tabular}

\begin{tabular}{|c|c|c|}
\hline $\begin{array}{l}\text { Variables } \\
\text { Correlation coefficient (significance) }\end{array}$ & $\begin{array}{c}\text { ED-FMD } \\
\text { rho, ( } P \text {-value })\end{array}$ & $\begin{array}{c}\text { El-FMD } \\
\text { rho, ( } P \text {-value })\end{array}$ \\
\hline Doppler PA systolic pressure (mm Hg) & $0.04,(0.803)$ & $0.14,(0.366)$ \\
\hline Doppler PA mean pressure $(\mathrm{mm} \mathrm{Hg})$ & $0.01,(0.362)$ & $0.06,(0.735)$ \\
\hline Invasive PA systolic pressures (mm Hg) & $0.07,(0.702)$ & $0.03,(0.884)$ \\
\hline Invasive PA mean pressures (mm Hg) & $0.14,(0.475)$ & $0.08,(0.685)$ \\
\hline PVR (Wood U) & $0.31,(0.127)$ & $0.31,(0.127)$ \\
\hline SVR (Wood U) & $0.03,(0.955)$ & $0.01,(0.967)$ \\
\hline PVR/SVR & $0.23,(0.253)$ & $0.22,(0.288)$ \\
\hline Six-minute walk distance (m) & $-0.09(0.544)$ & $0.08,(0.597)$ \\
\hline
\end{tabular}

the $3^{\text {rd }}$ minute were significantly different among groups $(p=0.001, p=0.001$, and $p=0.028$, respectively) (Fig. 2, Table 3).

Overall, the PH group showed significantly lower ED-FMD $(0.65 \pm 0.21$ vs. $0.30 \pm 0.23$ and $0.65 \pm 0.18$ vs. $0.24 \pm 0.21)$ and El-FMD ( $0.67 \pm 0.15$ vs. $0.37 \pm 0.25$ and $0.75 \pm 0.20$ vs. $0.32 \pm 0.24$ ) responses at the $1^{\text {st }}$ and $3^{\text {rd }}$ minutes $(p<0.001$ for all) than the controls. All these measures of ED-FMD and EI-FMD were comparable among IPAH, ES, and CTEPH subgroups (Table 4). Neither ED-FMD nor EI-FMD was correlated with functional class, 6MWD or targeted treatment status, echocardiography measures, PA pressures, pulmonary vascular and systemic vascular resistances, and pulmonary to systemic vascular resistance ratio ( $p>0.05$ ). Moreover, the percent changes in ED-FMD and EI-FMD showed weak correlations to pulmonary vascular resistance and pulmonary to systemic vascular resistance ratio with Spearman test (0.312 and 0.239, respectively) (Table 5).

\section{Discussion}

In this study, we demonstrated that brachial artery vasodilatory reserve assessed with ED-FMD (ischemia response) and
EI-FMD (nitrate response) was significantly impaired in patients with IPAH, Eisenmenger, and CTEPH than in healthy subjects. There was no difference in ED and El vasodilatory responses among the etiologic $\mathrm{PH}$ subgroups. However, these impairments in systemic arterial vasodilatory reserve were not correlated with the clinical and hemodynamic measures of pulmonary vascular disease severity. No significant difference was observed in ED-FMD (FMD\%) between the $1^{\text {st }}$ and $3^{\text {rd }}$ minutes.

The growing evidence from studies performed in patients with IPAH and scleroderma-PAH suggest the presence of a wide spectrum of systemic metabolic and inflammatory alterations and vascular dysfunction $(5,6,15-40)$ manifested by Impaired brachial artery vasodilatory reserve $(5,6,15-22)$. Blood flow abnormalities in the middle cerebral artery, reduced cerebrovascular reactivity to blood $\mathrm{PCO}_{2}$, decreased $\mathrm{NO}$ production by cerebral endothelial cells, impairment in perception of dyspnea and sleep-disordered breathing $(5,6,23-25)$. Disturbed reciprocal interaction among heart, lung and kidney due to maladaptive neurohormonal activation, oxidative stress, inappropriate immune signaling, and microalbuminuria $(5,6,26-28)$. Abnormal episcleral vascularization preceding the occurrence of PAH 15 , $6,29)$. Reduced capillary density in nailfold on capillaroscopy $(5$, $6,30)$. Lower blood flow index, increased tortuosity, and curvature in sublingual vessels (31). Skeletal myopathy characterized by ergoreflex overactivation related with reduced muscle strength due to switching from type I toward more fatigable type Il fibers, disturbed mitochondrial function and excitation-contraction coupling, increased muscle protein breakdown and decreased capillary density (5, 6, 32-36), and insulin resistance, diabetes, hypertriglyceridemia, and hyper- or hypothyroidism likewise in atherosclerotic cardiovascular diseases $(5,6,37-40)$. An increased ventilatory response to exercise as a result of the ergoreflex overactivation has been considered to be correlated with the severity of exercise intolerance and disease progression in PAH and heart failure, and benefits from PAH treatments and exercise training programs might be mediated by vasodilatation in skeletal muscles resulting in the reversal of muscle acidosis and modulation of ergoreflex $(5,6,32-36,44,45)$. 
The vascular pathologies of PAH including cell overgrowth, neointima formation, fragmentation of the elastic lamina, and vasoconstriction, muscularization, and calcium deposits in the large pulmonary arteries have also been reported in atherosclerotic cardiovascular diseases, aortic aneurysms, diabetic retinopathy, hypertensive nephropathy, and high-grade glioblastoma multiforme $(5,6,16,18)$.

When assessed with multiparametric approach, activation of BRD4 (bromodomain protein 4), a transcriptional regulator protein associated with pulmonary artery muscularization and calcification via activation of RUNX2 (Runt-related transcription factor 2) and cytokines, are considered to have contributions in accelerated coronary artery disease in patients with $\mathrm{PAH}$, and inhibition of abnormal BRD4 activity with apabetalone is proposed as a novel potential target for PAH treatment $(5,22)$.

Flow-mediated dilatation (FMD) was first described in femoral and brachial arteries and is mediated by potassium channel dependent release of $\mathrm{NO}$ produced from the nitroglycerine that leaks into the smooth muscle cells $(5,6,14-20)$. ED-FMD (ischemia response) assesses the hyperemia occurring in medium muscular arteries as a response to shear stress following ischemia induced by inflating the blood pressure cuff $(5,6,14-20)$. In patients with $\mathrm{PAH}$, studies with duplex ultrasound in BA revealed impaired FMD as a marker for systemic endothelial disfunction (5, 6, 14-20). Hughes et al. (17) reported significant reductions in BA FMD in $2.7 \%$ of patients with IPAH and $6.3 \%$ of patients with SSc-PAH, and a trend toward a reduced response in family members of the patients with IPAH. Peled et al. (18) documented impaired ED-FMD in patients with PAH, a correlation between the magnitude of the impairment and severity of disease as assessed by clinical and hemodynamic parameters. Wolff et al. (19) evaluated BA FMD in healthy controls and patients with PAH undergoing acute vasoreactivity testing with iloprost, and an impaired ED-FMD correlated with percent decrease in pulmonary vascular resistance with iloprost challenge was noted. However, in contrast to the study by Peled et al. (18), they found that impaired ED-FMD was not correlated with the hemodynamical severity of PAH (19).

Although our analyses confirmed the impairment in systemic vasodilatory reserve as assessed by ED-FMD and EI-FMD in all the patients with $\mathrm{PH}$ in accordance with the study by Wolff et al. (19); and in contrast to the study by Peled et al. (18), none of these impairments correlated with the echocardiographic, hemodynamic, and 6MWT measures of PH severity and targeted therapy (TT) status. Although ED-FMD was comparable among $\mathrm{PAH}$ subgroups, difference mechanisms might be involved in systemic endothelial dysfunction in these patients. Lower EDFMD in patients with Eisenmenger is considered to be a compensatory response to chronic hypoxia rather than caused by increased vasoconstrictor mediator levels. Nakamura et al. (20) reported that cardiovascular shunt lesions with increased pulmonary blood flow may be associated with a trend toward decreased cardiac output owing to decreased vascular wall shear stress and endothelial dysfunction. Besides, Ciftel et al. (41) found that compared with the control group, the mean FMD was significantly reduced in the cyanotic PH group. Further- more, polycythemia and hypoxia are considered to induce endothelial injury $(5,6,19)$. Lower ED-FMD in other subgroups might be caused by release of primary and secondary mediators. Interestingly, FMD was also found to be disturbed in patients with CTEPH similar to those in other PH subsets, and this finding suggests the presence of generalized endothelial dysfunction in the systemic circulation. Sirmagul et al. (42) showed that in monocrotaline (MCT) induced PH rats, the plasma NO level was not significantly different in the control and MCT groups; however, the iloprost and sildenafil treatments significantly decreased NO level in plasma. After administration of sublingual nitrate to evaluate EI-FMD, a significantly lower FMD was observed in all $\mathrm{PH}$ subgroups than in the controls. All the $\mathrm{PH}$ groups showed similar changes in the El-FMD response.

\section{Study limitations}

The design of the current study suffered from some limitations. First, the population size may be considered relatively small. However, majority of the previous data for FMD in patients with PAH have also been derived from studies having the same limitation (16-20). Uninterrupted PAH treatments targeted to three specific pathways because of ethical considerations might be another inevitable methodological limitation in the assessment of FMD in these patients; along with intra- and inter-observer variability of FMD method, daily changes according to biological circadian rhythm, and unsatisfactory signal to noise ratio related to artery diameter. The relationship between the measures of FMD and clinical, echocardiographic, and hemodynamic measures of PH severity was based on a cross-sectional analysis. Despite the absence of a relation between the impairment in FMD and these outcome measures at the time of assessments, long-term followup of these patients might provide more robust data regarding the prognostic impact of the impaired ED or El FMD on clinical course of $\mathrm{PH}$. The new guideline stated that it would be better to measure up to 5 minutes; however, the fact that it was done according to the previous guidelines at the time of study may have affected the results. Another limitation of study included taking single measurements at 1 and 3 minutes post deflation instead of the recommended continuous monitoring for the whole 180 seconds to find the peak vessel diameter (43). PAH-specific therapies that the patients received might affect the FMD measurements. In this analysis, all the patients had an intermediate risk in which the annual event rate expectation of $5 \%-10 \%$ according to the ESC/ ERS 2015 multiparametric risk algorithm. In addition, the clinical parameters could not be analyzed according to the patient groups owing to the low number of patients in groups. The clinical, hemodynamic, and neurohumoral relationship with Endotel function analysis was not performed because of the small number of patient in the groups.

\section{Conclusion}

Our results suggest significantly impaired BA vasodilatory reserve as assessed by ED-FMD and EI-FMD in patients with PH regardless of the etiological clinical subgroup and imply a general- 
ized vasodilatory dysfunction beyond the pulmonary vasculature. However, acute FMD may not reflect the severity of PH and cannot be used as a potential surrogate for outcome in this setting.

Acknowledgments: All the statistical analyses were performed by İbrahim Halil Tanboğa, MD, Professor of Cardiology and Assistant Professor of Biostatistics.

Declaration: This study was presented at the American College of Cardiology Scientific Sessions 2017 as a poster presentation titled, “The impaired endothelium-dependent and endothelium-independent systemic arterial vasodilatory reserve in pulmonary hypertension regardless of the clinical group" and was published in the Journal of the American College of Cardiology, 2017, 69(11):1905. DOI:10.1016/S07351097(17)35294-4.

\section{Conflict of interest: None declared.}

Peer-review: Externally peer-reviewed.

Author contributions: Concept - M.D., H.C.T., Ö.Y.A., A.H., Z.B., C.K; Design - M.D., Z.B.; Supervision - Z.B., N.Ö., C.K.; Fundings - None; Materials - M.D., H.C.T., Ö.Y.A., A.K., S.T., I.H.T., C.K.; Data collection \&/or processing - S..K., H.C.T., Ö.Y.A., A.K., S.T., B.Keskin, B.Kültürsay, S.Ç.E., C.K.; Analysis \&/or interpretation - Ş.K., A.K., S.T., B.Keskin, I.H.T., C.K.; Literature search - Ş.K., A.H., B.Keskin, B.Kültürsay, S.Ç.E., N.Ö., C.K.; Writing - A.H., B.Kültürsay, S.Ç.E., N.Ö., C.K.; Critical review - N.Ö., C.K.

\section{References}

1. Simonneau G, Gatzoulis MA, Adatia I, Celermajer D, Denton C, Ghofrani $A$, et al. Updated clinical classification of pulmonary hypertension. Turk Kardiyol Dern Ars 2014; 42 Suppl 1: 45-54. [Article in Turkish]

2. Galiè N, Humbert M, Vachiery JL, Gibbs S, Lang I, Torbicki A, et al.; ESC Scientific Document Group. 2015 ESC/ERS Guidelines for the diagnosis and treatment of pulmonary hypertension: The Joint Task Force for the Diagnosis and Treatment of Pulmonary Hypertension of the European Society of Cardiology (ESC) and the European Respiratory Society (ERS): Endorsed by: Association for European Paediatric and Congenital Cardiology (AEPC), International Society for Heart and Lung Transplantation (ISHLT). Eur Heart J 2016; 37: 67-119. [Crossref]

3. Simonneau G, Montani D, Celermajer DS, Denton CP, Gatzoulis MA, Krowka $M$, et al. Haemodynamic definitions and updated clinical classification of pulmonary hypertension. Eur Respir J 2019; 53: 1801913. [Crossref]

4. Galiè N, Channick RN, Frantz RP, Grünig E, Jing ZC, Moiseeva O, et al. Risk stratification and medical therapy of pulmonary arterial hypertension. Eur Respir J 2019; 53: 1801889. [Crossref]

5. Nickel NP, Yuan K, Dorfmuller P, Provencher S, Lai YC, Bonnet S, et al. Beyond the Lungs: Systemic Manifestations of Pulmonary Arterial Hypertension. Am J Respir Crit Care Med 2020; 201: 148-57. [Crossref]

6. Ranchoux B, Harvey LD, Ayon RJ, Babicheva A, Bonnet S, Chan SY, et al. Endothelial dysfunction in pulmonary arterial hypertension: an evolving landscape (2017 Grover Conference Series). Pulm Circ 2018; 8: 2045893217752912. [Crossref]

7. Krum H, Viskoper RJ, Lacourciere Y, Budde M, Charlon V. The effect of an endothelin-receptor antagonist, bosentan, on blood pressure in patients with essential hypertension. Bosentan Hypertension Investigators. N Engl J Med 1998; 338: 784-90. [Crossref]

8. Yardumian DA, Isenberg DA, Rustin M, Belcher G, Snaith ML, Dowd $P M$, et al. Successful treatment of Raynaud's syndrome with Iloprost, a chemically stable prostacyclin analogue. Br J Rheumatol 1988; 27: 220-6. [Crossref]

9. García de la Peña-Lefebvre P, Rodríguez Rubio S, Valero Expósito M, Carmona L, Gámir Gámir ML, Beltrán Gutiérrez J, et al. Longterm experience of bosentan for treating ulcers and healed ulcers in systemic sclerosis patients. Rheumatology (Oxford) 2008; 47: 464-6. [Crossref]

10. Berman S, Quick R, Yoder P, Voigt S, Strootman D, Wade M. Treprostinil sodium (Remodulin), a prostacyclin analog, in the treatment of critical limb ischemia: open-label study. Vascular 2006; 14: 142-8. [Crossref]

11. Goldstein I, Lue TF, Padma-Nathan H, Rosen RC, Steers WD, Wicker PA; Sildenafil Study Group. Oral sildenafil in the treatment of erectile dysfunction. 1998. J Urol 2002; 167: 1197-203. [Crossref]

12. Sueta CA, Gheorghiade M, Adams KF Jr, Bourge RC, Murali S, Uretsky BF, et al. Safety and efficacy of epoprostenol in patients with severe congestive heart failure. Epoprostenol Multicenter Research Group. Am J Cardiol 1995; 75: 34A-43A. [Crossref]

13. Meyer zu Vilsendorf A, Link C, Jörns A, Nagel E, Köhl J. Preconditioning with the prostacyclin analog epoprostenol and cobra venom factor prevents reperfusion injury and hyperacute rejection in discordant liver xenotransplantation. Xenotransplantation 2001; 8: 41-7. [Crossref]

14. Corretti MC, Anderson TJ, Benjamin EJ, Celermajer D, Charbonneau F, Creager MA, et al.; International Brachial Artery Reactivity Task Force. Guidelines for the ultrasound assessment of endothelialdependent flow-mediated vasodilation of the brachial artery: a report of the International Brachial Artery Reactivity Task Force. J Am Coll Cardiol 2002; 39: 257-65. [Crossref]

15. Joannides R, Haefeli WE, Linder L, Richard V, Bakkali EH, Thuillez $\mathrm{C}$, et al. Nitric oxide is responsible for flow-dependent dilatation of human peripheral conduit arteries in vivo. Circulation 1995; 91: 1314-9. [Crossref]

16. Friedman D, Szmuszkovicz J, Rabai M, Detterich JA, Menteer J Wood JC. Systemic endothelial dysfunction in children with idiopathic pulmonary arterial hypertension correlates with disease severity. J Heart Lung Transplant 2012; 31: 642-7. [Crossref]

17. Hughes R, Tong J, Oates C, Lordan J, Corris PA. Evidence for systemic endothelial dysfunction in patients and first-order relatives with pulmonary arterial hypertension. Chest 2005; 128 (6 Suppl): 617S. [Crossref]

18. Peled N, Shitrit D, Fox BD, Shlomi D, Amital A, Bendayan D, et al. Peripheral arterial stiffness and endothelial dysfunction in idiopathic and scleroderma associated pulmonary arterial hypertension. J Rheumatol 2009; 36: 970-5. [Crossref]

19. Wolff B, Lodziewski S, Bollmann T, Opitz CF, Ewert R. Impaired peripheral endothelial function in severe idiopathic pulmonary hypertension correlates with the pulmonary vascular response to inhaled iloprost. Am Heart J 2007; 153: 1088.e1-7. [Crossref]

20. Nakamura M, Yoshida H, Naganuma Y, Kon H, Sugawara S, Hiramori K. Peripheral vasodilatory dysfunction in adult patients with congenital heart disease and severely elevated pulmonary vascular resistance. Angiology 2002; 53: 715-20. [Crossref]

21. Shimony A, Eisenberg MJ, Rudski LG, Schlesinger R, Afilalo J, Joyal $D$, et al. Prevalence and impact of coronary artery disease in patients with pulmonary arterial hypertension. Am J Cardiol 2011; 108: 460-4. [Crossref] 
22. Ruffenach G, Chabot S, Tanguay VF, Courboulin A, Boucherat 0 , Potus $F$, et al. Role for Runt-related Transcription Factor 2 in Proliferative and Calcified Vascular Lesions in Pulmonary Arterial Hypertension. Am J Respir Crit Care Med 2016; 194: 1273-85. [Crossref]

23. Malenfant S, Brassard P, Paquette M, Le Blanc 0, Chouinard A, Nadeau $V$, et al. Compromised Cerebrovascular Regulation and Cerebral Oxygenation in Pulmonary Arterial Hypertension. J Am Heart Assoc 2017; 6: e006126. [Crossref]

24. Treptow E, Oliveira MF, Soares A, Ramos RP, Medina L, Lima R, et al. Cerebral microvascular blood flow and $\mathrm{CO} 2$ reactivity in pulmonary arterial hypertension. Respir Physiol Neurobiol 2016; 233 : 60-5. [Crossref]

25. Minic M, Granton JT, Ryan CM. Sleep disordered breathing in group 1 pulmonary arterial hypertension. J Clin Sleep Med 2014; 10: 277-83. [Crossref]

26. Husain-Syed F, McCullough PA, Birk HW, Renker M, Brocca A, Seeger W, et al. Cardio-Pulmonary-Renal Interactions: A Multidisciplinary Approach. J Am Coll Cardiol 2015; 65: 2433-48. [Crossref]

27. O'Leary JM, Assad TR, Xu M, Birdwell KA, Farber-Eger E, Wells OS, et al. Pulmonary hypertension in patients with chronic kidney disease: invasive hemodynamic etiology and outcomes. Pulm Circ 2017; 7: 674-83. [Crossref]

28. Nickel NP, de Jesus Perez VA, Zamanian RT, Fessel JP, Cogan JD, Hamid $\mathrm{R}$, et al. Low-grade albuminuria in pulmonary arterial hypertension. Pulm Circ 2019; 9: 2045894018824564. [Crossref]

29. Watanabe M, Makino S, Obata H. Bilaterally dilated episcleral vessels in patients with heritable pulmonary arterial hypertension. $\mathrm{J}$ Gen Fam Med 2017; 18: 464-5. [Crossref]

30. Corrado A, Correale M, Mansueto N, Monaco I, Carriero A, Mele $A$, et al. Nailfold capillaroscopic changes in patients with idiopathic pulmonary arterial hypertension and systemic sclerosisrelated pulmonary arterial hypertension. Microvasc Res 2017; 114: 46-51. [Crossref]

31. Dababneh L, Cikach F, Alkukhun L, Dweik RA, Tonelli AR. Sublingual microcirculation in pulmonary arterial hypertension. Ann Am Thorac Soc 2014; 11: 504-12. [Crossref]

32. Malenfant S, Potus F, Fournier F, Breuils-Bonnet S, Pflieger A, Bourassa $S$, et al. Skeletal muscle proteomic signature and metabolic impairment in pulmonary hypertension. $\mathrm{J}$ Mol Med (Berl) 2015; 93: 573-84. [Crossref]

33. Potus F, Malenfant S, Graydon C, Mainguy V, Tremblay È, BreuilsBonnet $S$, et al. Impaired angiogenesis and peripheral muscle microcirculation loss contribute to exercise intolerance in pulmonary arterial hypertension. Am J Respir Crit Care Med 2014; 190 : 318-28. [Crossref]
34. Malenfant S, Potus F, Mainguy V, Leblanc E, Malenfant M, Ribeiro F, et al. Impaired Skeletal Muscle Oxygenation and Exercise Tolerance in Pulmonary Hypertension. Med Sci Sports Exerc 2015; 47: 2273-82. [Crossref]

35. Müller-Mottet S, Hildenbrand FF, Keusch S, Hasler E, Maggiorini M, Speich $\mathrm{R}$, et al. Effects of exercise and vasodilators on cerebral tissue oxygenation in pulmonary hypertension. Lung 2015; 193: 11320. [Crossref]

36. Grünig E, Eichstaedt C, Barberà JA, Benjamin N, Blanco I, Bossone $E$, et al. ERS statement on exercise training and rehabilitation in patients with severe chronic pulmonary hypertension. Eur Respir J 2019; 53: 1800332. [Crossref]

37. Benson L, Brittain EL, Pugh ME, Austin ED, Fox K, Wheeler L, et al. Impact of diabetes on survival and right ventricular compensation in pulmonary arterial hypertension. Pulm Circ 2014; 4: 311-8. [Crossref]

38. Zamanian RT, Hansmann G, Snook S, Lilienfeld D, Rappaport KM, Reaven $\mathrm{GM}$, et al. Insulin resistance in pulmonary arterial hypertension. Eur Respir J 2009; 33: 318-24. [Crossref]

39. Brittain EL, Talati M, Fessel JP, Zhu H, Penner N, Calcutt MW, et al. Fatty Acid Metabolic Defects and Right Ventricular Lipotoxicity in Human Pulmonary Arterial Hypertension. Circulation 2016; 133: 1936-44. [Crossref]

40. Scicchitano P, Dentamaro I, Tunzi F, Ricci G, Carbonara S, Devito F, et al. Pulmonary hypertension in thyroid diseases. Endocrine 2016; 54: 578-87. [Crossref]

41. Ciftel M, Simşek A, Turan 0, Kardelen F, Akçurin G, Ertuğ H. Endothelial dysfunction and atherosclerosis in children with irreversible pulmonary hypertension due to congenital heart disease. Ann Pediatr Cardiol 2012; 5: 160-4. [Crossref]

42. Sirmagul B, Ilgin S, Atli O, Usanmaz SE, Demirel-Yilmaz E. Assessment of the endothelial functions in monocrotaline-induced pulmonary hypertension. Clin Exp Hypertens 2013; 35: 220-7. [Crossref]

43. Thijssen DH, Black MA, Pyke KE, Padilla J, Atkinson G, Harris RA, et al. Assessment of flow-mediated dilation in humans: a methodological and physiological guideline. Am J Physiol Heart Circ Physiol 2011; 300: H2-12. [Crossref]

44. Kaymaz C, Akbal OY, Hakgor A, Tokgoz HC, Tanyeri S. Dart to the target: an alternative bull's eye parametric display for European Society of Cardiology / European Respiratory Society goal-orientated risk reduction strategy in pulmonary arterial hypertension. Pulm Circ 2018; 8: 2045894018780522. [Crossref]

45. Kaymaz C, Mutlu B, Küçükoğlu MS, Kaya B, Akdeniz B, Kılıçkıran Avcı B, et al. Preliminary results from a nationwide adult cardiology perspective for pulmonary hypertension: RegiStry on cllnical outcoMe and sUrvival in pulmonaRy hypertension Groups (SIMURG). Anatol J Cardiol 2017; 18: 242-50. [Crossref] 